\title{
Article
}

\section{Development of a Novel Design Strategy for Moving Mechanisms Used in Multi-Material Plastic Injection Molds}

\author{
Fátima de Almeida ${ }^{1}\left(\mathbb{D}\right.$, Vitor F. C. Sousa $^{1}$, Francisco J. G. Silva ${ }^{1,2, * \mathbb{C}}$, Raúl D. S. G. Campilho ${ }^{1,2}{ }^{(\mathbb{D}}$ \\ and Luís P. Ferreira ${ }^{1,2}$ (D) \\ 1 ISEP-School of Engineering, Polytechnic of Porto, Rua Dr. António Bernardino de Almeida, 431, \\ 4249-015 Porto, Portugal; faf@isep.ipp.pt (F.d.A.); vcris@isep.ipp.pt (V.F.C.S.); \\ raulcampilho@gmail.com (R.D.S.G.C.); luispintoferreira@eu.ipp.pt (L.P.F.) \\ 2 INEGI-Instituto de Ciência e Inovação em Engenharia Mecânica e Engenharia Industrial, \\ 4200-465 Porto, Portugal \\ * Correspondence: fgs@isep.ipp.pt
}

Citation: Almeida, F.d.; Sousa, V.F.C.; Silva, F.J.G.; Campilho, R.D.S.G.; Ferreira, L.P. Development of a Novel Design Strategy for Moving Mechanisms Used in Multi-Material Plastic Injection Molds. Appl. Sci. 2021, 11, 11805. https://doi.org/ 10.3390/app112411805

Academic Editor: Roberto Zivieri

Received: 15 November 2021 Accepted: 10 December 2021 Published: 12 December 2021

Publisher's Note: MDPI stays neutral with regard to jurisdictional claims in published maps and institutional affiliations.

Copyright: (c) 2021 by the authors. Licensee MDPI, Basel, Switzerland. This article is an open access article distributed under the terms and conditions of the Creative Commons Attribution (CC BY) license (https:// creativecommons.org/licenses/by/ $4.0 /)$.

\begin{abstract}
Plastics injection molding is a sector that is becoming increasingly competitive due to the environmental issues it entails, pressuring consumers to reduce its use. Thus, plastics processing companies attempt to minimize costs, with the aim of increasing competitiveness. This pressure is transmitted to the mold manufacturers, as the mold conditions the equipment that it is used for, which may have significantly different amortization costs. The present work aimed to design a novel mechanism able to deal with the necessary movements in $2 \mathrm{~K}$ injection molding in a more compact way. A novel hybrid mechanical and hydraulic movement was developed. More compact movements lead to smaller molds, which can be used on smaller injection machines, leading to reduced costs. This methodology consists of multiplying a disproportionate movement to the mold through several movements, which results in a slightly more complex, but much more compact, system for molds devoted to multi-material injected parts.
\end{abstract}

Keywords: bi-injection; multi-injection; mold; mold movements; mold design; movements design; mechanical design; improving mold design; competitiveness

\section{Introduction}

Molds are an indispensable tool for obtaining parts of both metals and plastics by injection [1,2]. The evolution of molds over time has been remarkable, both in terms of materials and wear resistance [3], as well as in terms of simulation, allowing the final product quality to be improved [4,5]. The complexity of the obtained shapes requires extra efforts from the field of engineering to find effective and economical solutions that are able to satisfy the demanding requirements of customers. Moreover, molds are intended to have the smallest possible volume, as this allows them to be used in injection machines with a shorter distance between columns, a factor that enhances greater mold use flexibility [6]. Thus, solutions that were valid a few years ago, tend to become obsolete due to the aforementioned constraints; these challenges became even more difficult with the advent of bi-injection [7]. Therefore, mold space are increasingly important, and creative solutions for injecting two different materials are now necessary. It is from this perspective that this work arises, the main objective of which is to the design a new solution capable of occupying less space that allows for the necessary bi-injection requirements.

Injection molding is the most used manufacturing process for producing parts in thermoplastic polymers; in a single process it can convert raw material into a part or component that is ready to be used or applied [8]. The optimization of parameters or the identification of the most critical parameters of the process, with the aim of increasing quality and productivity, continue to be some of the most studied topics, with several techniques being applied in order to obtain this optimization, namely a combination 
of the hybrid back-propagation neural network and intelligent algorithms [9], learning decision models from offline data [10], feature selection methods [11] or 3D finite element simulation [12]. Usually, researchers seek to increase the cooling of the mold after injection to decrease the cycle time. Indeed, the mold is subjected to cyclic waves of temperature and heating when the polymer is injected and must rapidly decrease the temperature to allow the solidification of the molded part; therefore, the cooling rate should be as short as possible, shortening the cycle time. To achieve this, the mold is provided with inner channels able to allow cold water to flow and decrease the temperature in the cavities. However, researchers attempted to decrease the typical warpage of the molded products when the geometry and injection conditions were not optimized. Tang et al. [13] used Taguchi techniques to minimize the effect of warpage on a specific product, having carried out nine different experiments using the polymer melting temperature, filling time, holding pressure, and holding time as variables. After identifying the most appropriate values for each parameter under those specific conditions, the authors concluded that the parameter with the greatest influence on the warpage was melting temperature, concluding that the filling time essentially does not influence the results. Park and Dang [14] studied the use of conformal cooling channels in plastic injection molds to cool the places where the mold quickly produced thicker walls in the part. This cooling process was designed based on the introduction of inserts in the mold, which were produced through Selective Laser Melting (SLM) processes. The introduction of conformal cooling channels allowed for a reduction in cycle time by $30 \%$ when compared to conventional cooling techniques. This technique also allowed for more accurate temperature monitoring in places where these inserts were applied, allowing the system to become intelligent through the circulation of water in the channels appropriate to the registered temperature levels. The influence of injection parameters on the mechanical properties of the parts obtained was also studied through a Design of Experiments (DoE) by Farotti and Natalini [15], using polypropylene as a raw material. In this study, it was emphasized that the mechanical properties of polypropylene are essentially conditioned by the mold temperature and packing pressure. However, the latter should not be excessive, as being under penalty of the injected parts can exhibit fragile behavior.

Mold wear is another constant concern for researchers. Zabala et al. [16] started from the typical classification of wear mechanisms normally attributed to molds, then studied the effect of mold cavity surface treatment, considering the injection of different polymers, such as reinforced polyamide, thermoplastic polyester, or acrylic resin. In the molds, there is usually abrasion created by the entrainment of particles, additives or reinforcements included in the injected plastic flow, or erosion when the polymer flow collides with the mold walls head-on during the filling phase. These wear mechanisms must also be joined by corrosion, as some polymers and additives are increasingly aggressive in conventional steels. In the study by Zabala et al., the Ni-PTFE coating significantly improved performance in terms of corrosion resistance, while the TiN coating caused a reduction in the friction of polymer flow and a better performance in terms of abrasion and erosion resistance.

The introduction of fibers enabled new applications for thermoplastic polymers, but also created new problems to be solved: the wear of molds and some components of injection machines [17]. This wear and how to minimize it is the subject of several studies, which essentially involve the use of coatings. Thus, studies were published that argued that TiB2 coatings made by PVD had excellent wear minimizing characteristics, significantly extending mold life $[18,19]$. However, other studies suggested coatings of $(\mathrm{Cr}, \mathrm{Al}) \mathrm{N} /(\mathrm{Cr}$, Al) ON [20], TiAlSiN [9] or CrN/CrCN/DLC [21]. Even using high levels of short fiberglass as reinforcement, these PVD-coated molds demonstrated in practical terms a significant increase in wear resistance, having shown very low levels of wear. In fact, these coated molds showed almost imperceptible levels of wear when compared to uncoated steel mold cavities, even after having performed triple injections. 
Regarding mold design, one of the critical tasks is the identification of the parting line, due to the often-complex geometry of the part that is produced. Fu et al. [22] developed a methodology based on the visibility and moldability of the surface. To this end, they defined an algorithm that starts by identifying and defining the core, the cavity, the local tool-molded surfaces, and, based on those, establishes the most suitable parting line for the part in question. This is a very complex phase in the process of creating a mold, so algorithms of this nature are extremely useful to the designer, saving a lot of design time and avoiding possible design errors. This model has been successfully tested in practice, so it can be used even on complex parts. The previous group of authors, in a work published five years earlier [23], used additions and found that the parting lines, core mechanisms, lifters, sliders and the overall structure of the mold were conditioned by the quantity and geometry of the undercuts that the part requires for the mold. To resolve this constraint at the design stage, these researchers developed software capable of automatically recognizing and identifying undercuts based on geometric characteristics and the relationship with the surfaces molded from the 3D model of the part. The ideal partition direction is selected based on the proposed criterion of considering the number of possible undercuts and the respective volume of each undercut.

Molds remain tools that are subjected to a very high number of thermal cycles, which cause the induction of internal stresses in molds and in produced parts. Tang et al. [24] studied the design of molds considering their thermal analysis and corresponding thermal gradients in the mold and parts. In view of the developed study, it was possible to conclude that there is a greater shrinkage probability of parts in places closer to cooling channels, when compared to other regions of the mold. Thus, the localized cooling of the part may be subject to the main warpage effect, due to these thermal gradients. Thus, if thermal analyzes are carried out, which, through thermal simulation, allows the identification of the existence, type and location of thermal gradients that are developed for a part, it is possible to act on the mold design to avoid the appearance of warpage. The design of ejection systems for molded parts was also the subject of research [25]. To this end, a new procedure was developed that was capable of automatically creating the layout and measuring the necessary ejection pins according to the 3D model of the part to be molded. This algorithm is based on the analysis of the difference in thickness between each node-mesh pair, locating the zones with thickness variation. Thus, the areas where the ejectors can be placed are identified, as well as their size and shape. The same team of researchers recently published another work [26], now showing the development of an algorithm capable of automatically generating cooling channels. In this case, in addition to recognizing part topology, the algorithm needed to consider the amount of heat was to be transferred, as well as the corresponding places, designing and dimensioning the cooling system so that heat was drained from the part uniformly, avoiding the above-listed defects.

The plastic injection molding industry has continued to innovate and respond to the growing demand of consumers in terms of functionality, comfort and product innovation; injection cycles were grouped, enabling what is known as multi-material injection molding. Usually, in the first stage, a thermoplastic is injected, and then an elastomer is often injected to give the part new functionality or to increase its wearing comfort. This technique brings new challenges, due to the need for compatibility between the injected materials and the corresponding thermal cycles. To make this possible, there must be different cavities. The first cavity enables the molding of the first material, usually more rigid (thermoplastic or thermosetting); and the second cavity enables the introduction of the first part that is already molded, having the necessary free space for the molding of the second material, which is normally compliant. There are several ways to move from the first to the second phase, with some technological progress in the meantime. Initially, the first molded parts had to be transferred from one initial cavity to another (where the second material/molding was performed) [26]. Technology has evolved and rotating molds are now common; they are provided with the necessary cavities and movements that make multi-material injection molding possible without having to extract the first molded parts 
from the cavity where they were made. Clearly, this situation depends on the geometry of the part that is obtained. Currently, there are essentially three possible techniques for making multi-material injection molding: cavity transfer, removable core, and sliding core methods [27]. The cavity transfer technique is less demanding in terms of mold design; on the contrary, it requires a precise handling system for the initially molded parts. The removable core technique does not require manipulation of the parts, as it is only required that the core move. However, the use of this technique has limitations in terms of the geometry to which it can be applied. In the sliding core method, the entire cavity of the part is extracted from the initial mold volume and sliding cores are purposefully placed inside the mold to restrict or activate flows in certain zones. The design of the mold becomes more complex, but the freedom to accommodate more complex geometries is far superior, requiring no manipulation.

Multi-material molding thus implies movements with standard solutions, which are currently supplied by manufacturers of standard mold parts. However, these solutions usually require a lot of space in the area surrounding the mold cavities, implying that the same mold is bulkier, more expensive, and that it requires a larger injection machine. Some of the solutions usually proposed by the suppliers of handling systems are shown in Figure 1.

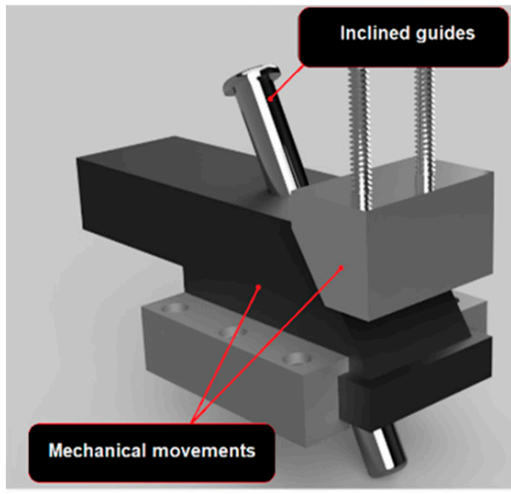

(a)

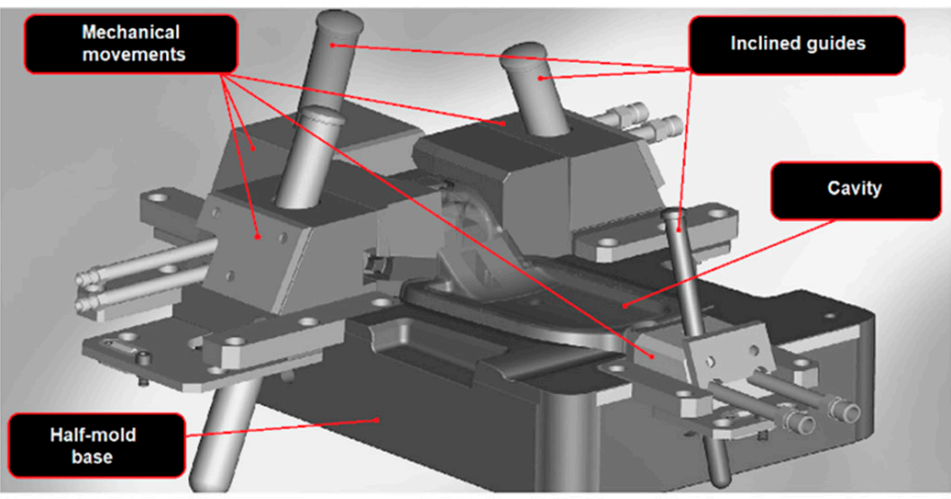

(b)

Figure 1. Molding injection movement systems $(\mathbf{a}, \mathbf{b})$ usually provided by suppliers as standard products.

The technical and scientific literature on this topic is quite scarce, although the process is currently used due to its enormous potential to join two different materials in a single part without the need for any assembly operation. Due to this lack of information on molds for multi-material injection molding, and due to the permanent use of oversized injection machines, the need was realized for a novel concept of hybrid movement for this kind of mold, which allows significant space to be saved through the simplification of mechanisms in the core movements. This work is organized into five sections. Section 2-Materials and Methods, describes the challenges, the approaches used and the case study that allows for the validation of the novel design. Section 3 presents the Results. Section 4 promotes a discussion around the results achieved. Finally, Section 5 highlights the main findings achieved through this work.

\section{Materials and Methods}

This work aimed to develop and describe an innovative mechanism integrated in a mold for multi-material injection molding. To demonstrate the implementation of the novel concept of movement, a part with a demanding geometry was chosen because it involved complex mechanical movements.

\subsection{Part Definition}

The part used to develop the concept consists of two distinct components injected in the same cavity and in two distinct shots; the part must reach a high level of quality while 
meeting all the requirements imposed by end customers. It will be incorporated in a child protection seat which is used in motor vehicles and will be made of two different polymeric materials, one for each component: PolyPropylene (PP) and High-Density PolyEthylene (HDPE). The 3D model of the part is shown in Figure 2. The total mass of the part is $29.9 \mathrm{~g}$, distributed as follows: $26.7 \mathrm{~g}$ of PP and $3.2 \mathrm{~g}$ of HDPE. These values were obtained based on the 3D modeling of the part using SolidWorks ${ }^{\circledR}$ software, with the volume and density of the PP being $27.81 \mathrm{~cm}^{3}$ and $0.96 . \mathrm{g} / \mathrm{cm}^{3}$, respectively, and the volume and density of the HDPE being $3.52 \mathrm{~cm}^{3}$ and $0.91 \mathrm{~g} / \mathrm{cm}^{3}$, respectively.

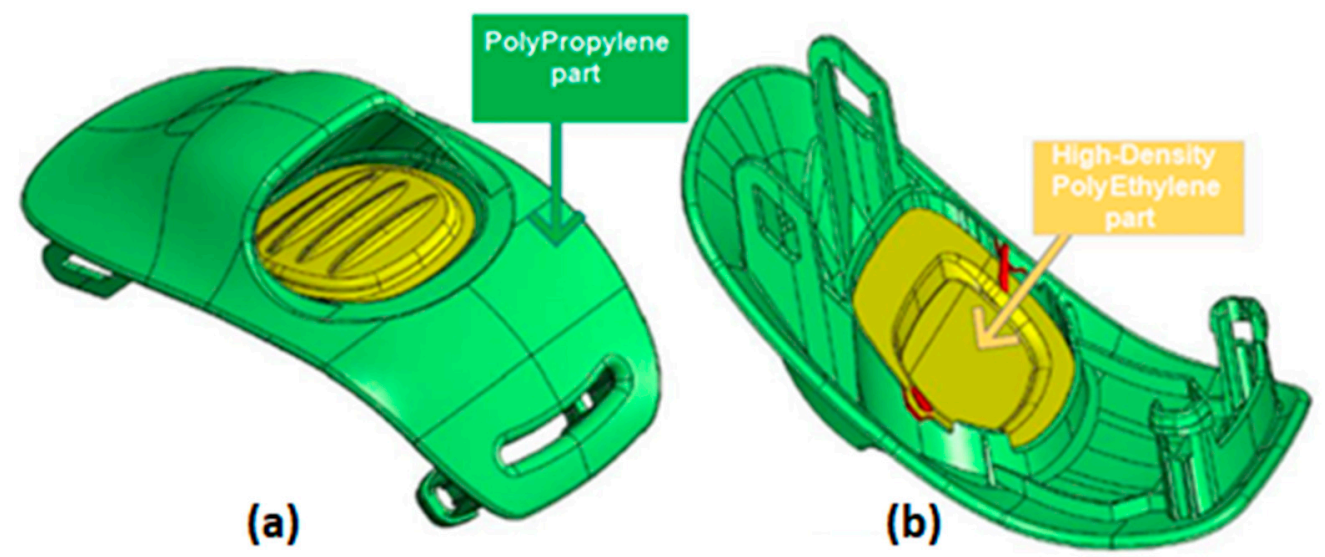

Figure 2. 3D model of the part and material distribution (a) PP in green color; (b) HDPE in yellow color.

It should be noted that both components of the final part maintain an approximately constant thickness throughout their geometry, which improves the quality of injection, avoiding warpage and other small imperfections, as well as allowing a better material flow during injection. A detailed analysis was performed on the 3D model of the part, verifying the need for the use of inclined lifters (Figure 3a) and vertical lifters (Figure 3b) to allow the creation and extraction of some complex shapes of the part, as a function of the selected parting line, indicated by the red boxes in Figure 3. The injection zones were imposed by the customer and can be seen in Figure 4.
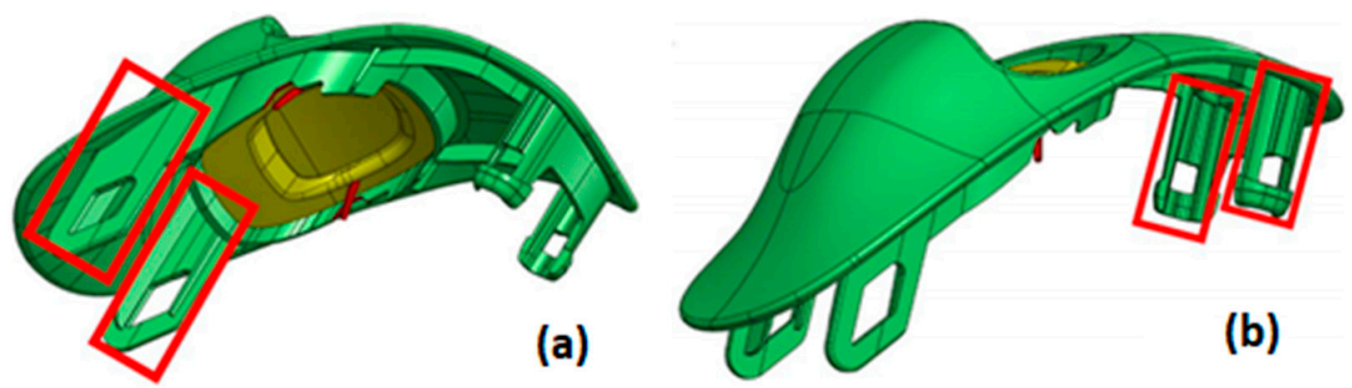

Figure 3. Identification of the zones where lifters are needed: (a) inclined lifters; (b) vertical lifters.

\subsection{List of Requirements for the Mold}

Usually, customers provide a list of requirements which must be followed in order to homogenize their stock of molds, to make their maintenance easier and for mold compatibility with customer-owned machines. The list of requirements this specific mold must meet are shown in Table 1. The mold will have two independent injection systems, each one responsible for injecting one of the two raw materials. Priority should be given to parts extraction by mechanical movements, rather than hydraulic movements, as they are more economical. The mold guide should be a traditional one, with cylindrical guides. Static inserts must contain the same material and treatment as the molding plates. Elements or components subject to movement, such as sliding systems, must contain thermal or 
surface treatment, such as nitriding, to increase resistance to wear, corrosion and facilitate the sliding itself. For extraction movements with an inclination greater than $10^{\circ}$, the doublerack side action method [28] for extraction movements should be used, as it is use space efficiently in these situations.

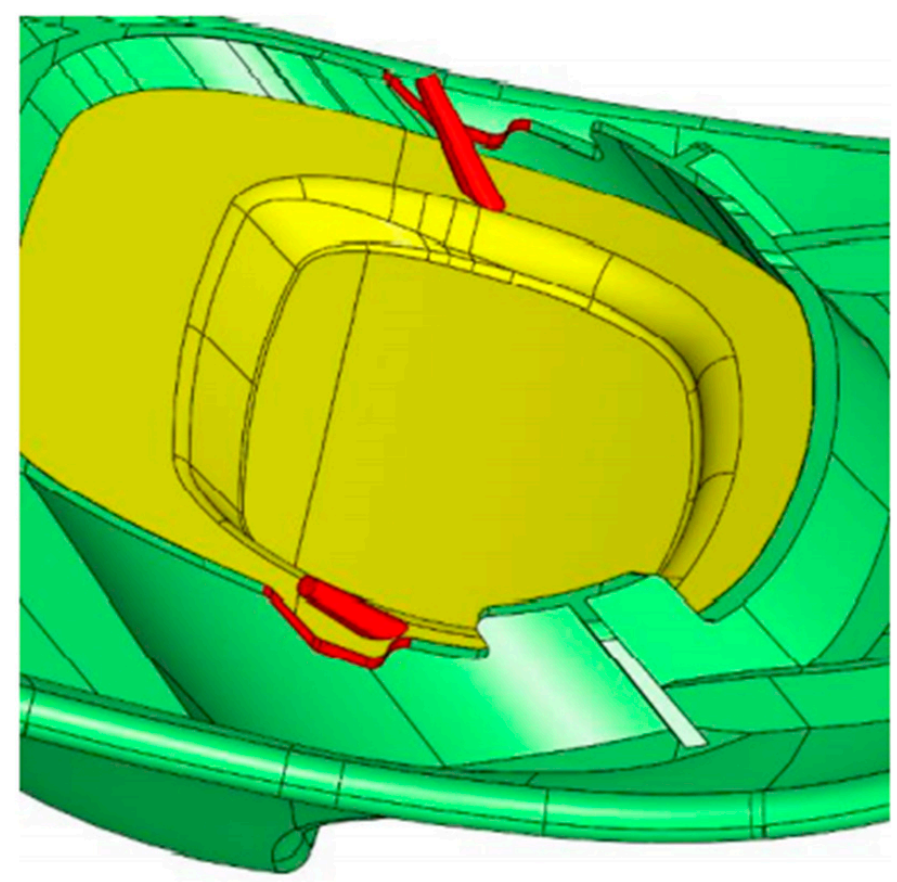

Figure 4. Injection zones imposed by the end customer (red marks).

Table 1. Requirements and specifications established by the mold customer.

\begin{tabular}{cc}
\hline Title 1 & Title 2 \\
\hline Clamping load & $200 \mathrm{t}$ \\
\hline Injection machine type & Bi-material \\
\hline Distance between machine guides & $670 \mathrm{~mm}$ \\
\hline Mold height & $370 \mathrm{~mm}$ \\
\hline Maximum mold opening including mold \\
height & $1050 \mathrm{~mm}$ \\
\hline Radius of the injectors & $19 \mathrm{~mm}$ \\
\hline Centering diameter & $200 \mathrm{~mm}$ \\
\hline Number of cavities & 2 \\
\hline Cycle time & $40 \mathrm{~s}$ \\
\hline Ejection system & Conventional, on the movable side, with \\
\hline Part removal & hydraulic drive \\
\hline Minimum estimated production & Krauss Maffei 200 Bi-Material \\
\hline Machine brand and model & 1.2738 steel and AMPCO 83 alloy \\
\hline Mold structure & 1.2738 steel \\
\hline Mold cavities & data \\
\hline entry 2 & 1.2738 steel and AMPCO 83 alloy \\
\hline
\end{tabular}


The part consists of two distinct polymers, so each one has its own linear contraction (1.6\% for PP and $2.8 \%$ for HDPE). To compensate for this, regarding the contraction that the part will undergo after being completely cooled and extracted from the mold, it is necessary to consider that the PP part represents $89.3 \%$ of the total mass, which will have a scale factor associated with its 3D design of 1.016, while the part in HDPE will have a scale factor associated with its 3D design of 1.028 .

\subsection{Simulation}

To determine filling time, holding time, and holding pressure, a study was carried out based on the SolidWorks Plastics ${ }^{\circledR}$ software to verify if the points indicated as preferred by the customer were exactly those that best met the part filling needs. This study was carried out by avoiding possible conflicts between the local space of the runners and the space needed to place the new mechanisms involved in the movements. It should be noted that the mold will inject two parts per injection cycle, i.e., it will have two molding zones arranged in such a way to allow its subsequent extraction vertically, in relation to the engraving surface. To perform the simulation, the following characteristics were defined for the injection nozzles: channel diameter: $5 \mathrm{~mm}$ (both materials); nozzle diameter: $1.5 \mathrm{~mm}$ (both materials); submarine injection point diameter: $0.9 \mathrm{~mm}$ (PP) and $1.0 \mathrm{~mm}$ (HDPE). For the purposes of simulation, the properties of SABIC ${ }^{\circledR}$ PP PHC26 were considered, as this is the raw material provided for PP injections. When studying the Shear Rate vs. Viscosity, there is a clear perception that there is a maximum limit of 100,000/s to be met for the shear rate, since, from this value, the viscosity presents an unstable and unwanted behavior. This observation occurred from previous experience with this kind of polymer. After some simulations, it was possible to verify that the PP injection point should be changed, since the location proposed by the customer is not the most advisable, as it is susceptible to causing complications due to its positioning on the part. Whenever possible, the injection point should be close to one end, as it is more economical to produce and direct the injection flow in a more controlled manner. The new selected areas for injection can be seen in Figures 5 and 6, representing the progress of the material during the injection process. The simulation made it possible to establish a filling time of $1.23 \mathrm{~s}$, a holding time of $5.5 \mathrm{~s}$, and a holding pressure of $6.3 \mathrm{MPa}$.

The simulation also made it possible to verify that the welding lines would be in the non-exposed points of the final part, which satisfies the customer's requirements. In addition, there is a gradient of about $20^{\circ} \mathrm{C}$ in front of the injected material which, although not ideal, clearly does not represent problems for the welding line. The PP section of the part is subject to a shear rate of approximately $40,360 / \mathrm{s}$, which is evidently below the maximum allowable rate: 100,000/s. The surface depressions in the part were also checked, and they did not exceed $0.2 \mathrm{~mm}$ in depth.

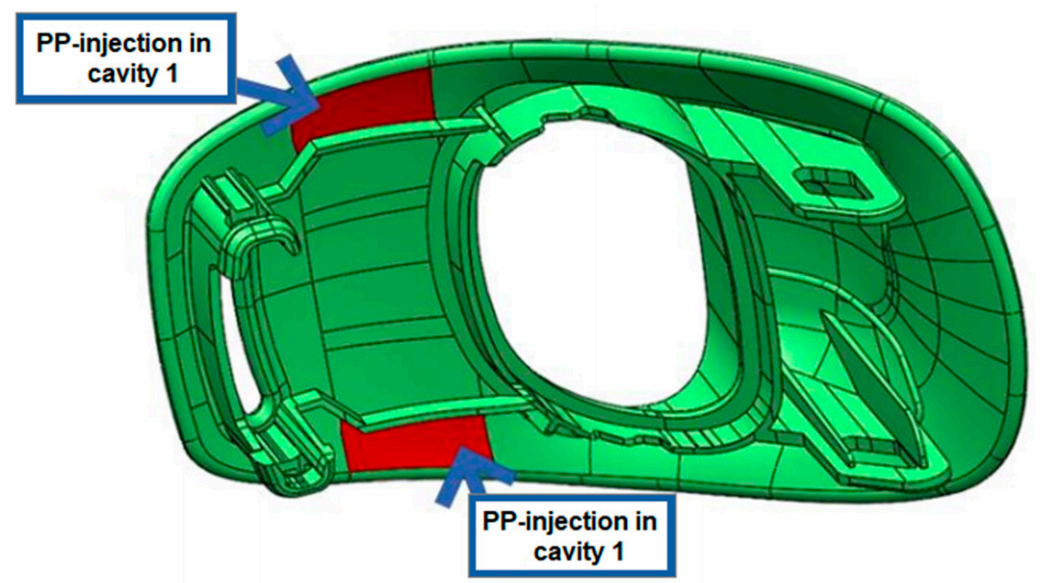

Figure 5. Injection zones imposed by the end customer (red marks). 

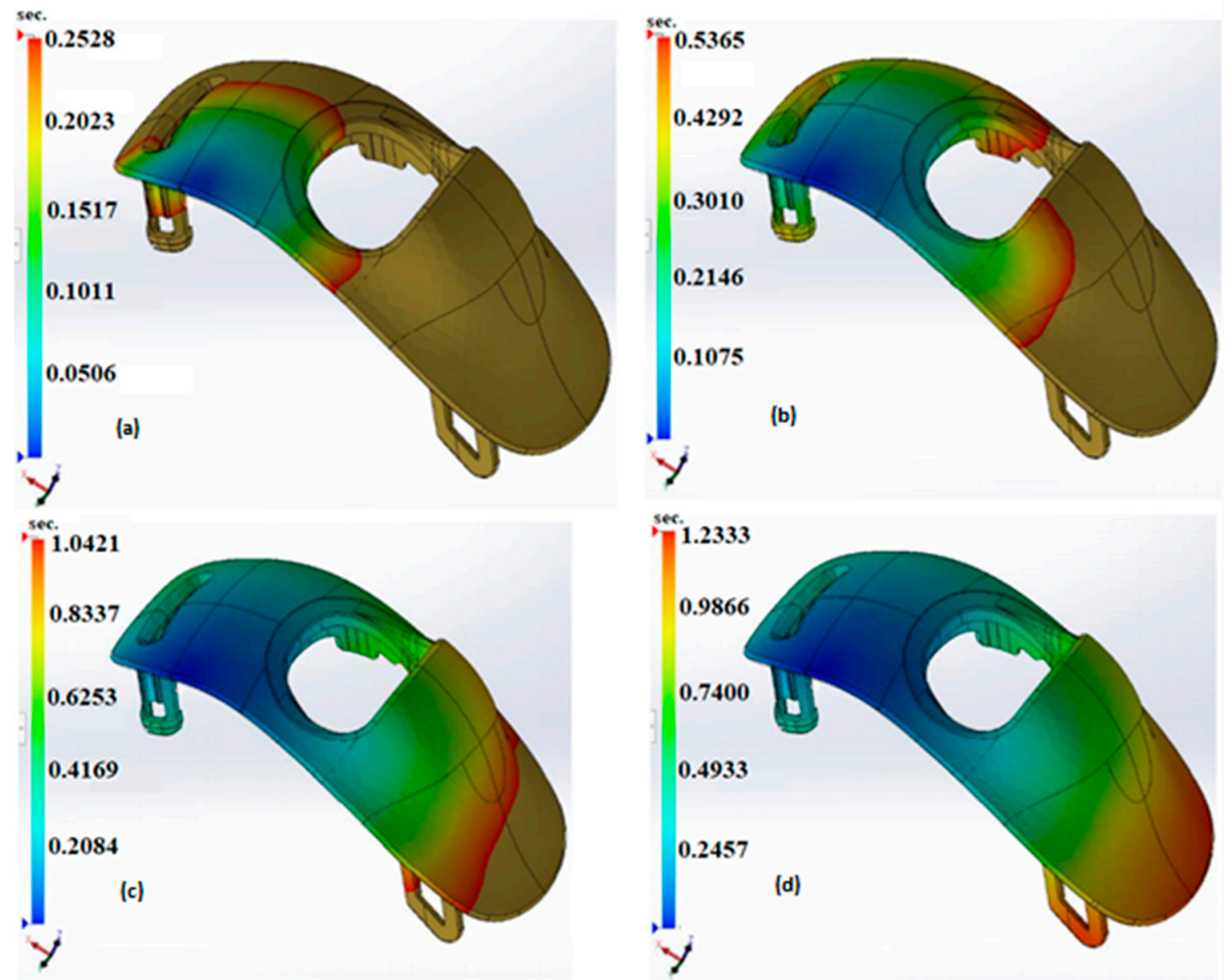

Figure 6. Simulation of PP filling progress using SolidWorks Plastics ${ }^{\circledR}$ considering the following filling rates: (a) $25 \%$, (b) $50 \%$, (c) $75 \%$ and (d) $100 \%$.

The same study was carried out for the injection in HDPE. For this, the characteristics announced by REGIDEX ${ }^{\circledR}$ (provider) for the raw material with the reference HD 6070EA were considered. The maximum permissible shear rate, as in the case of PP, is 100,000/s for HDPE. Figure 7 represents the progress of the material during the injection process. The simulation made it possible to calculate the filling time $0.49 \mathrm{~s}$, for the holding time of $6.4 \mathrm{~s}$ and holding pressure of 7.8 MPa.

The HDPE section of the part is subject to a shear rate of approximately $40,360 / \mathrm{s}$, which is well below the maximum allowable rate: $100,000 / \mathrm{s}$. The surface depressions in the part were also checked, and they did not exceed $0.08 \mathrm{~mm}$ in depth.

\subsection{Mold Movements}

After properly analyzing the part and its requirements, it was possible to verify that it required four extraction movements, in order to promote the required lifting function. In addition to this, it is also necessary to include an insert for the component in HDPE, so that it was possible to make a movement that allows the injection of PP first, and then the HDPE. The part in PP is engraved directly on the mold, while the part in HDPE is made through an insert that has two positions, alternating between the two through a hydraulic drive mechanism. The first position of this insert is when it is closed, allowing only the material flow, fill the existing space for the PP. After the PP has solidified, the insert descends about $4.7 \mathrm{~mm}$ to its second position, thus making room for the HDPE to flow and fill its due volume, as can be seen in Figure 8. 

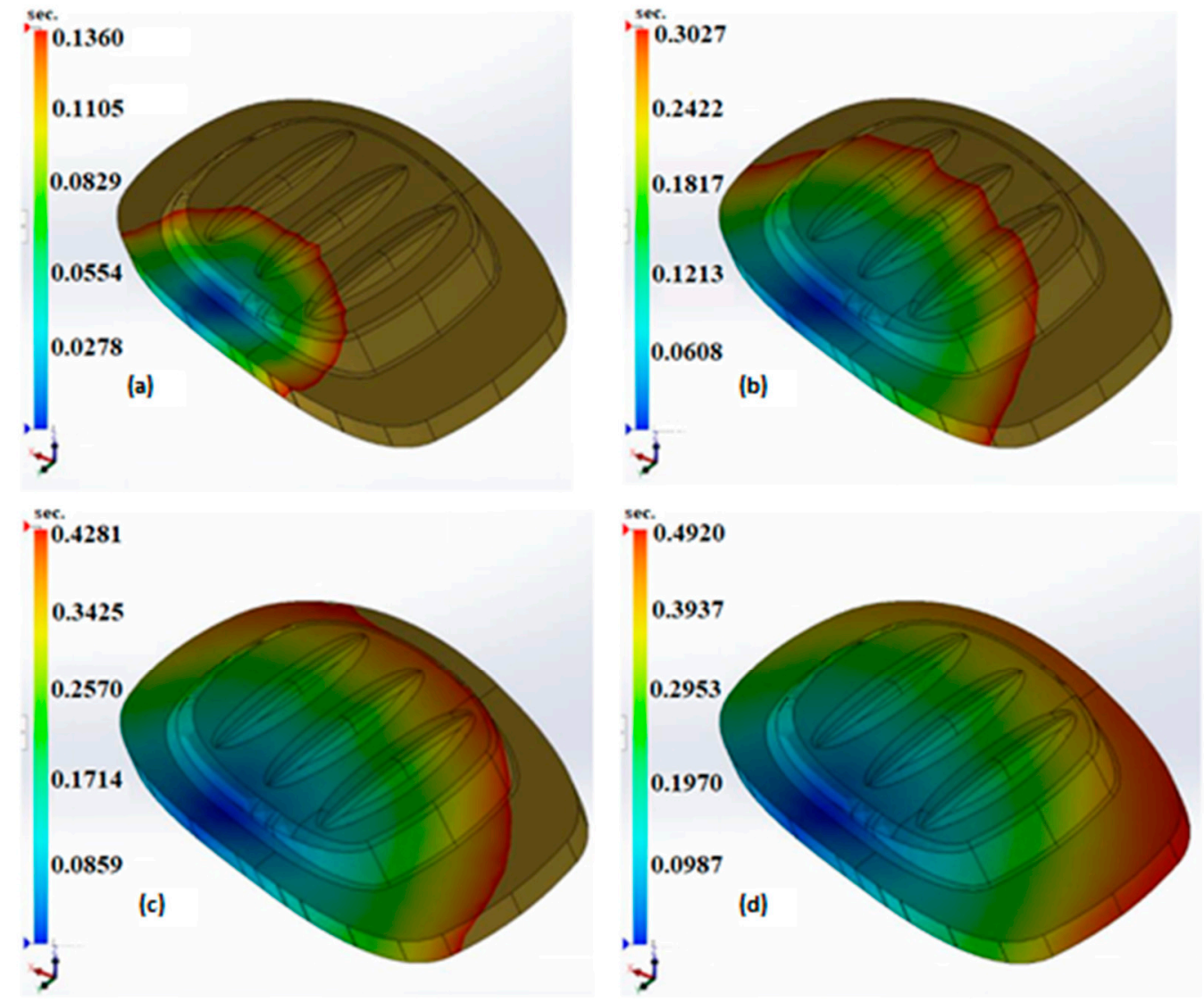

Figure 7. Simulation of HDPE filling progress using SolidWorks Plastics ${ }^{\circledR}$ considering the following filling rate (a) $25 \%$, (b) $50 \%$, (c) $75 \%$ and (d) $100 \%$.

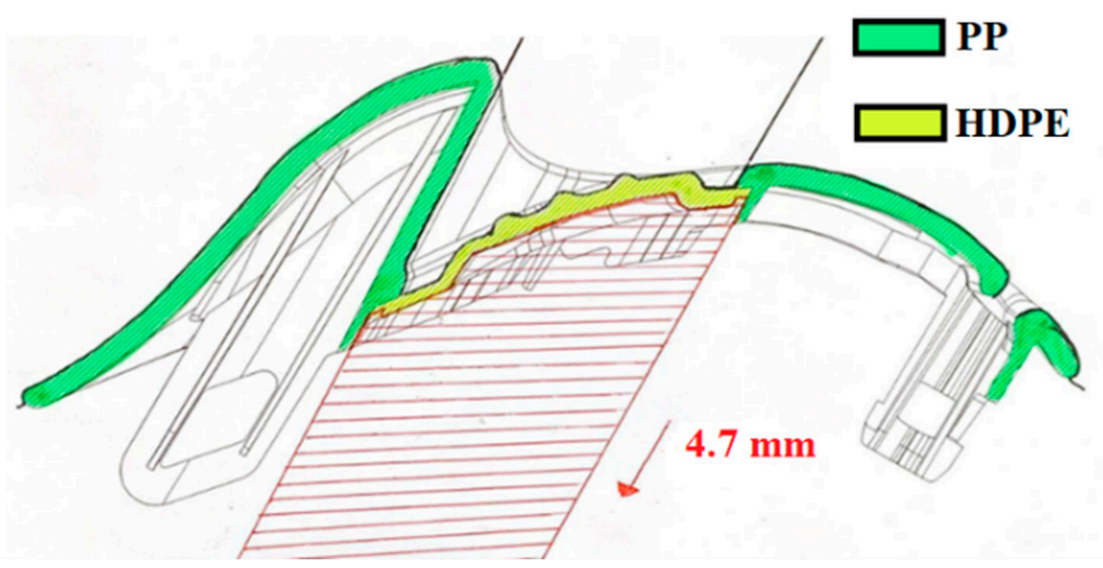

Figure 8. Injection zones imposed by the end customer (red marks).

\subsection{Research Approach}

Because the literature is very scarce on this subject, a scientific methodology, usually called "action-research" was adopted, in which the action researcher and a customer work together in the analysis of the problem and in the development of a solution based on the previous analysis. To fulfill the above-mentioned conditions and avoid the use of standard/commercial movement systems which take up a lot of space and imply the growth of the global dimensions of the mold, a new idea arose based on the joint use of mechanical and hydraulic systems. The hydraulic system has the necessary strength to promote a short movement, but, under an intense load, the mechanical system converts the direction of movement, taking it to the place where it is needed, avoiding collisions with 
other existing systems in the mold. The great advantage of this system is that it is easily adaptable to each type of mold, promoting small movements where a relatively high load is required.

The novelty of this work is that it focuses on the system that can move the insert between one position and another, in order to create the necessary space for the HDPE to be injected. As discussed in the Introduction section, there are standard sub-sets available on the market; however, they require the need for more space to be assembled in the molds, increasing mold volume, and requiring the use of a larger injection machine due to the limited space between guiding columns.

The real novelty of this project is in the way that the bi-injection system is designed in a compact way using a vertical mechanical movement in relation to the part. This is driven by a hydraulic movement perpendicular to the mechanical movement. For this project, a novel concept was developed which consisted of a hybrid movement (per cavity), i.e., a combined method of mechanical movement and hydraulic movement, so that it was possible to better use the space occupied by the mechanism responsible for the extraction movement. A hydraulic movement positioned horizontally in relation to the part was used, combined with a mechanical movement positioned perpendicularly to the hydraulic movement (shown in Figure 9). With this arrangement, it is possible to optimize the space required by extractors and lifters, promoting the other necessary movements in the space initially left free for such extractors and lifters. This hybrid movement is innovative in this kind of mold and there are no references to any similar system in the previous literature. All of this takes place in a conventional mold format, which has: (a) two molding plates, (b) two extraction plates, (c) two fixing plates, (d) an intermediate plate and (e) a pair of shims.
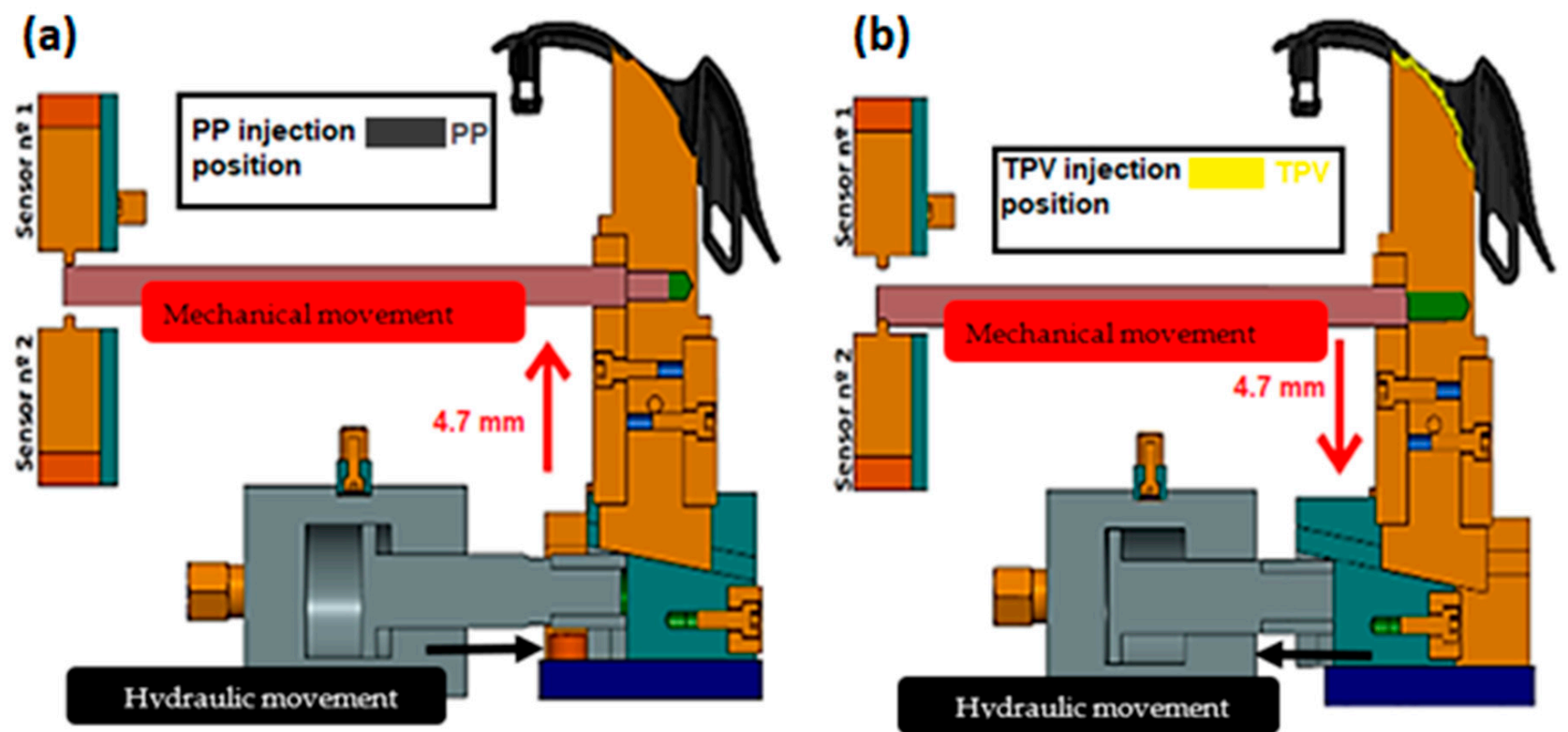

Figure 9. Scheme of the innovative combination of movements: injection position of (a) PP and (b) HDPE.

\section{Results}

Important details were worked on to improve the quality of the mold/part, in addition to reducing costs. There are design concepts used in this project, which involved four movements to perform extraction. The description of these movements is as follows:

- Modulation and extraction of the part;

- Alternation of the injection of two materials, translation movement, and hydraulic actuation for each cavity. 


\subsection{Modulation and Extraction of the Part}

For a better understanding of the work developed, all the elements responsible for the extraction of the parts are presented. Each extraction element has two horizontal extraction movements, two vertical lifters $\left(\right.$ at $\left.90^{\circ}\right)$ and two lifters with a $4^{\circ}$ inclination in relation to a vertical axis.

In the horizontal extraction movements, the guides for each of these movements have the function of guidance/orientation, during opening and closing, especially when forcing the forward position. When the mold is open, other movements with springs (located at the top of the mold) have the function of keeping them in the retreat position. In this position, as they are against the direction of gravity, they must, together with the moving part of the mold, be kept in that position when the guide is apart, while the movements below need only to touch a cylindrical head screw (standard M8 screw) to limit the lineage of these two movements to their opening position. These four horizontal movements use a microswitch, with the function of counting the opening and closing cycles, to control the life of the components and the mold in general. The backward movement of these movements ranges from 0 (closed or backward position) up to $45 \mathrm{~mm}$, allowing the demolding of parts and the vertical lifting movement, represented in Figure 10.

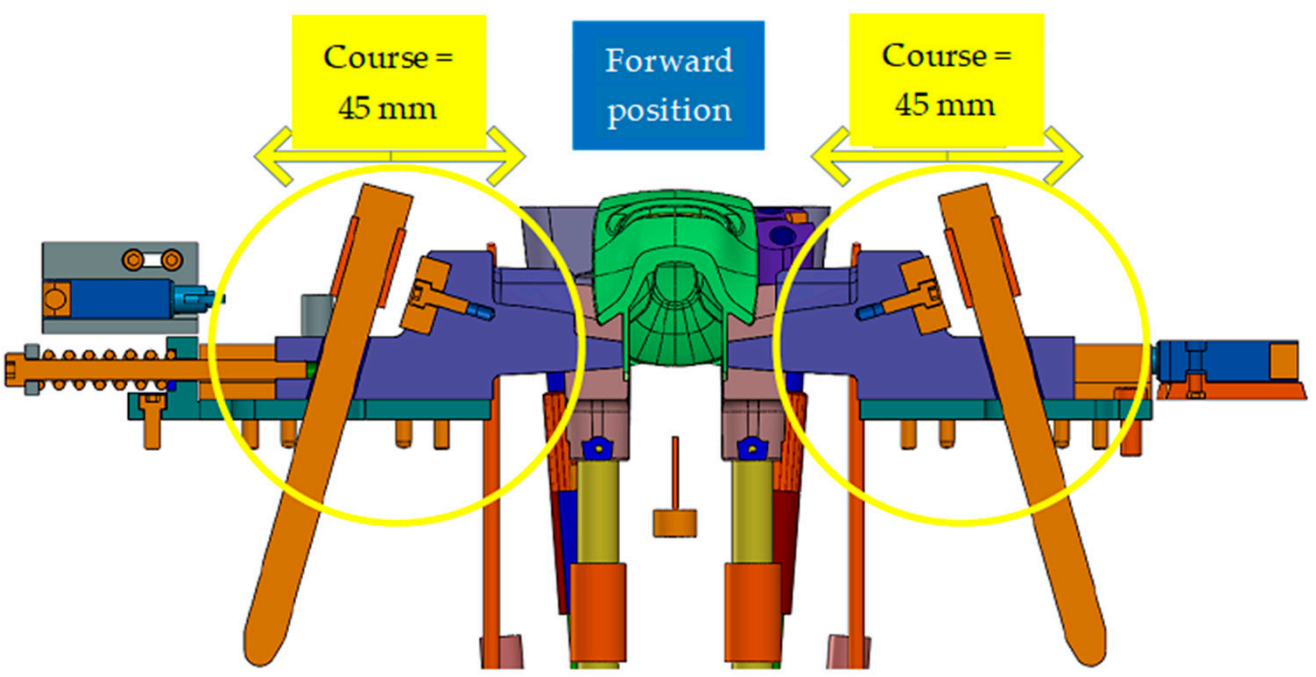

Figure 10. Horizontal extractors (section view).

The extraction sequence of the parts begins with the opening of the moveable part of the mold (injection side), which, together with the movement guides, moves to the backward position. The mold remains in this position until the parts are removed sequentially by the mold lifters, through the movement of the extraction plates. Only then the moveable part of the mold returns to the closed position, forcing the guides to follow the movements, thus returning to the forward positions.

Figure 11 shows, on the right side, a horizontal movement in its front position, ready to shape the PP, and, on the left side, another movement in the backward position. The guide increases more at the opening of the mold, but from that point, visible in the image, it will no longer make the return movement. On the other hand, lifters are simpler movements to extract the parts. The four inclined lifters (Figure 12 yellow parts) perform an inclined extraction, being fixed to the mechanism on the extraction plates. This causes the lifters to have a diagonal stroke, with an inclination of $4^{\circ}$ relative to the vertical line of the mold. These lifters are of the "oscillating" type or with a double axis, with an angle of inclination less than $10^{\circ}$ and space in the extraction plates, necessary for applying this type of extraction. 


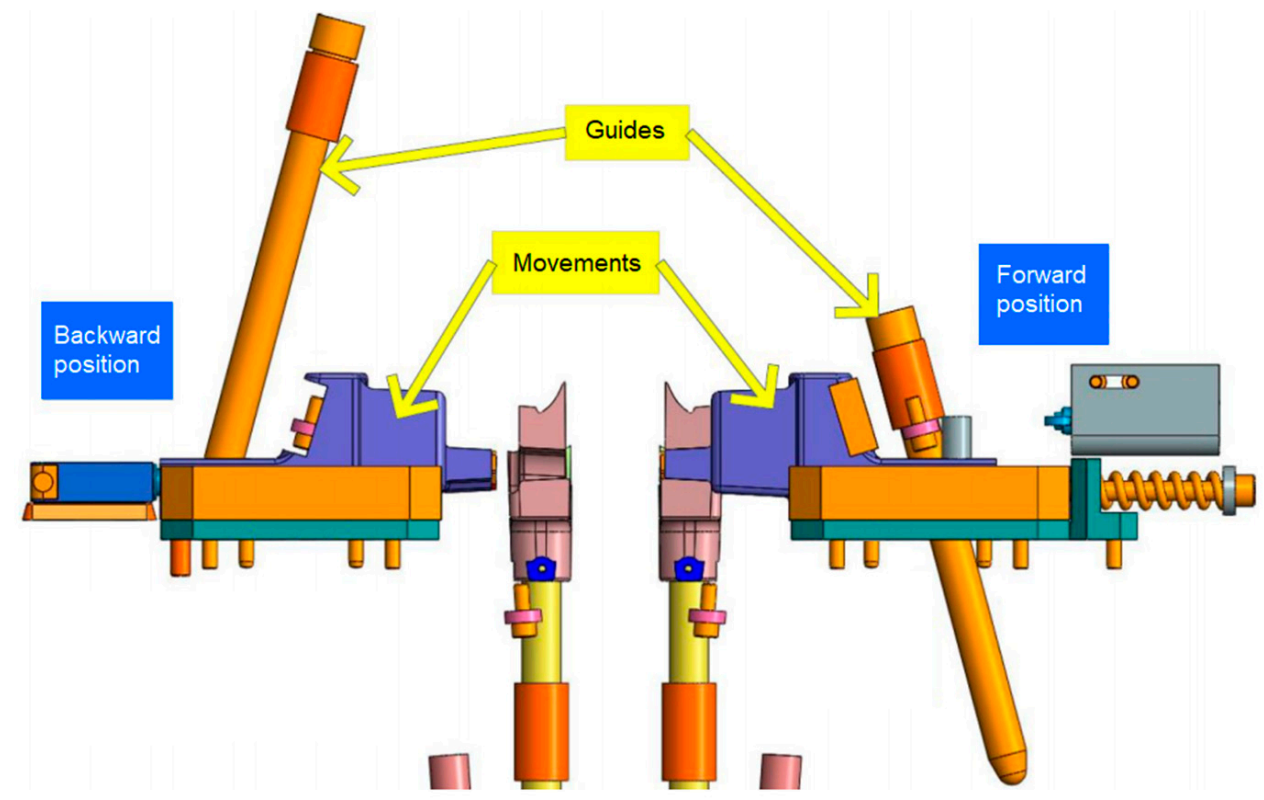

Figure 11. Horizontal extractors (section view).

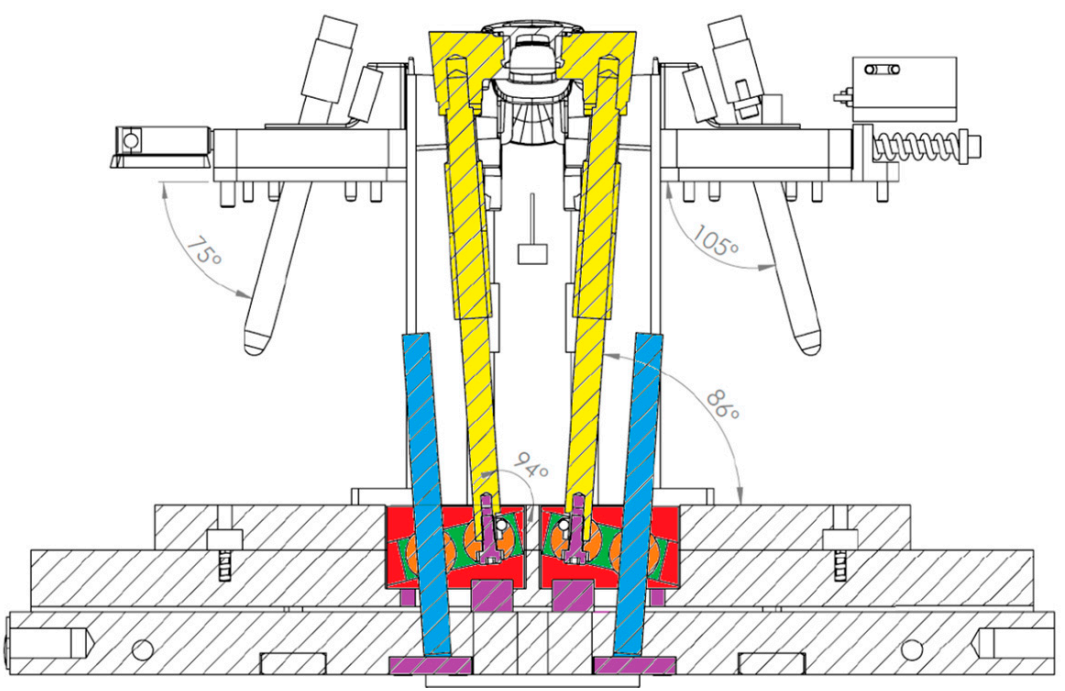

Figure 12. Technical drawing of the lifters with $4^{\circ}$ inclination (sectional view).

The extraction plates, when going forward, fed by the hydraulic system, take the blades with them (red color, Figure 12). These rise to $90^{\circ}$, so that the lifters rise diagonally, causing an inclination of $86^{\circ}$ or $94^{\circ}$ (Figure 12). The mechanism inside the slides (green and orange) has the function of laterally moving the base of the body of these lifters (yellow), so that the base of the lifters follows its diagonal line. Thus, the guides (blue) and the fixed part of the mechanism (orange and green), guide the base of the lifter body (yellow), since the rest of the mechanism is guided by the engraving plate on the extraction side.

\subsection{Alternation of Injection of Two Materials}

Both the HDPE engraving inserts, and the extraction plates, have hydraulic movements, four in total: two type- 1 cylinders for the inserts and two type-2 cylinders for the extraction plates, as shown in Figure 13. Type-2 cylinders are designed to perform the extraction movement. They are more robust components because they are exposed on the outside of the mold, and are different from type 1 cylinders, which are inside the mold. Thus, type- 1 cylinders are more compact and adjusted to the movements of the inserts. 


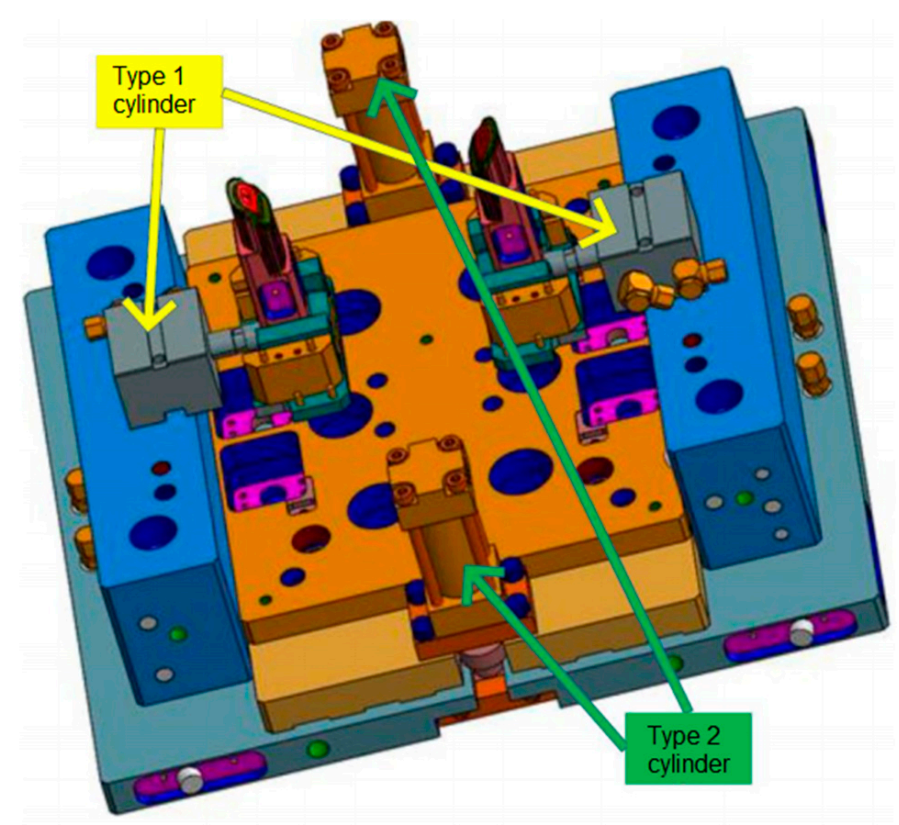

Figure 13. Hydraulic structure with type-1 and type-2 cylinders positioning.

The two type- 2 cylinders, responsible for advancing and withdrawing the extraction plates, use the back plate on the extraction side as a fixed base, and the rest are fixed to the extraction plates. Thus, when the piston advances, the cylinder causes the plates to rise by $45 \mathrm{~mm}$, which is necessary for extracting the parts. A similar process occurs in type-1 cylinders. However, they are attached to the engraving plate on the extraction side and cause the mechanism to move, in which, as the pistons of these cylinders' advance, the two HDPE engraving inserts rise by $4.7 \mathrm{~mm}$ (Figure 14), leaving free the space to now be injected with the HDPE component. Type- 1 and type-2 cylinders' advance and retract similarly, but at different stages of the injection cycle. Type-1 performs the backward movement when injecting HDPE, after injecting PP. Then, type-2 performs the forward movement of the components responsible for the extraction needed for them to function, followed by the reverse movement. After the type- 2 cylinders retract the extraction plates, the type- 1 cylinders remove the inserts. At the same time, the mold is closed by the injection machine, starting a new injection cycle. Type- 1 cylinders have a maximum pressure capacity of 500 bar and a minimum of 80 bar, being able to press a force of $1025.1 \mathrm{~kg}$ in the advance and $715.02 \mathrm{~kg}$ in the return (for a diameter of $40 \mathrm{~mm}$ ). Thus, even with additions, due to the friction and pressure loss of the hydraulic pump itself, with these cylinders operating at 80 bar, these pressures are expected to be more than sufficient for advancing and retracting the $1.41 \mathrm{~kg}$ of each one of the engraving inserts responsible for molding the HDPE components.

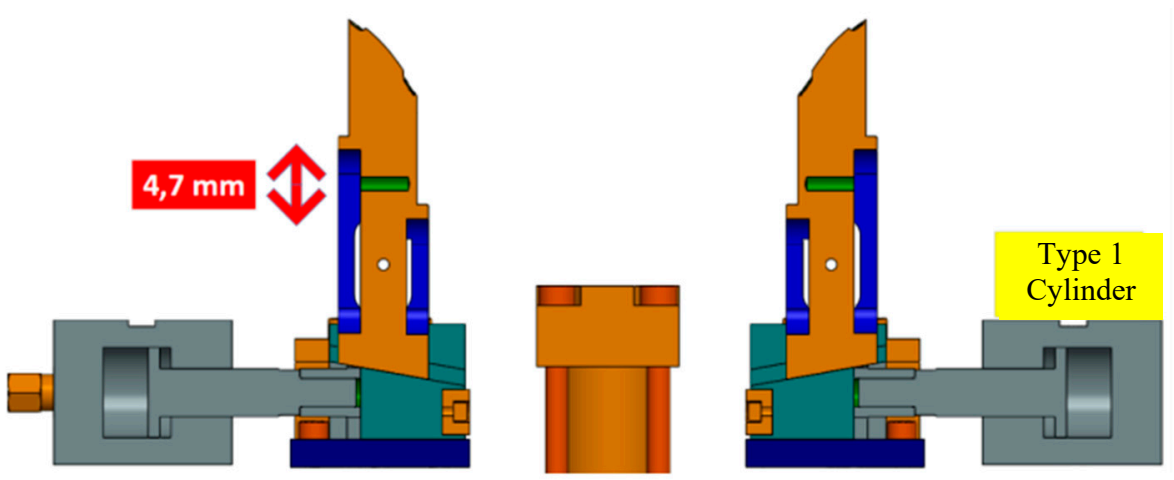

Figure 14. Hybrid hydraulic/mechanical movement of HDPE engraving inserts. 
In the most advanced position, the injection pressure of PP laterally affects the insert. The hydraulic supports this pressure because the force is applied vertically. When the hydraulic is in the backward position, the vertical injection pressure (from HDPE) already affects the insert, but since it is in the resting position, it is mechanically supported, and so can easily resist the pressure applied to it. Thus, hydraulic cylinder type-1 (simple) requires only the minimum pressure (standard). Type-2 cylinders share the same maximum and minimum pressure limits (500 and 80 bars, respectively).

Considering the two extraction plates, it is necessary to move a mass of $74.02 \mathrm{~kg}$, plus about $6.3 \mathrm{~kg}$ of the components and the friction that they cause. Even so, the sum of these portions does not justify the need for high pressures, since the hydraulic performs a forward load in the order of $2050.02 \mathrm{~kg}$ and a backward load of $1430.04 \mathrm{~kg}$ for a diameter of $40 \mathrm{~mm}$. Thus, a pressure of $160 \mathrm{bar}$ is sufficient, within the limits of the cylinder.

The extraction plates have more functionality than the extraction of the injected parts. Because they are plates of considerable dimensions (with about a $74 \mathrm{~kg}$ load), they require an element that guides their movements in a precise and independent way. The solution was to add four guide plates, one in each corner. This solution is identical to the standard guide of the mold structure itself, which consists of placing four fixed bushings between the extraction plates and, concentrically to those, four guides that are fixed to the back-plate on the extraction side of the mold.

One of the other functions that these plates contain is return pins. They are simple extractors, placed at the possible ends of the mold, and aligned with the closing line. In this way, safety in the mold, in case that the extraction plates do not recede during the injection cycle, is guaranteed. These return pins are the first and only element to hit the mold elements on the injection side, and withstand the closing forces, in order not to damage the lifters. Otherwise, they would cause significant damage to the mold, with aggravated losses, in relation to the repair of simple extractors. Another feature of these extraction plates are the supports, which aim to provide a greater resistance to the mold, in order to guarantee its integrity throughout its useful life. The remaining elements that these plates contain, and that justify their existence, are the four vertical lifters (Figure 15), the four inclined lifters and the four channel pullers (Figure 16).

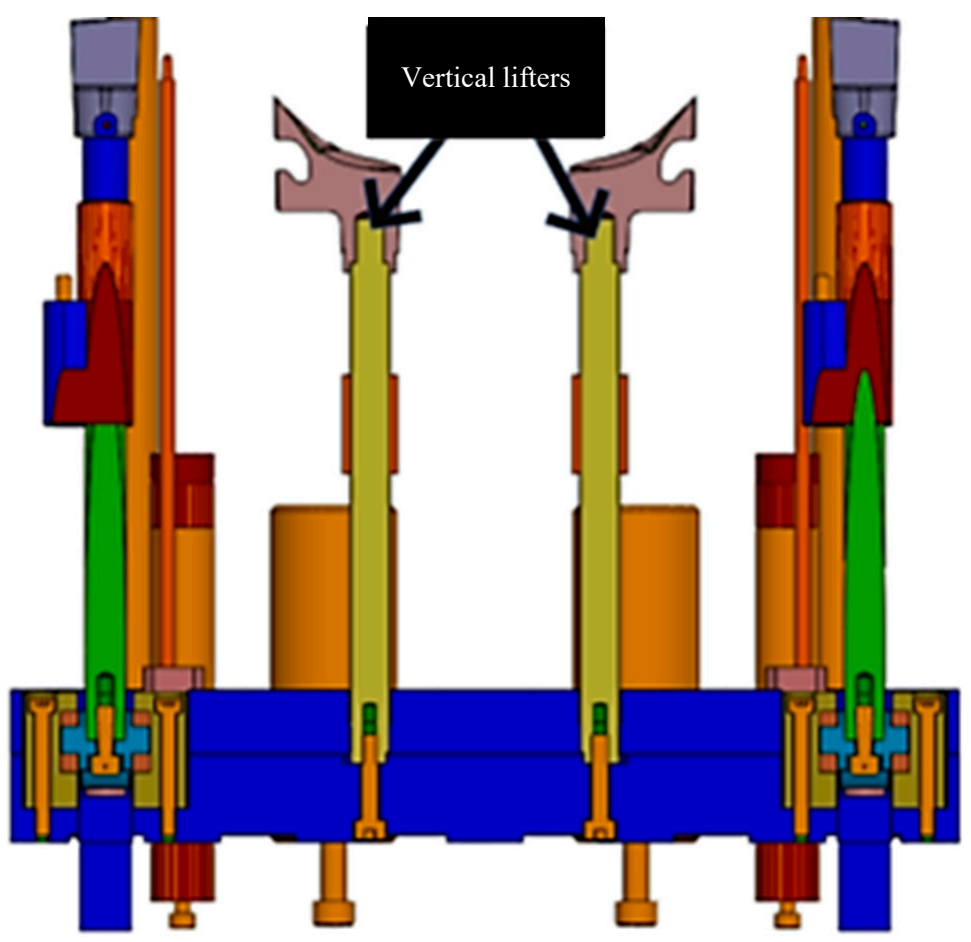

Figure 15. Vertical lifters (sectional view). 


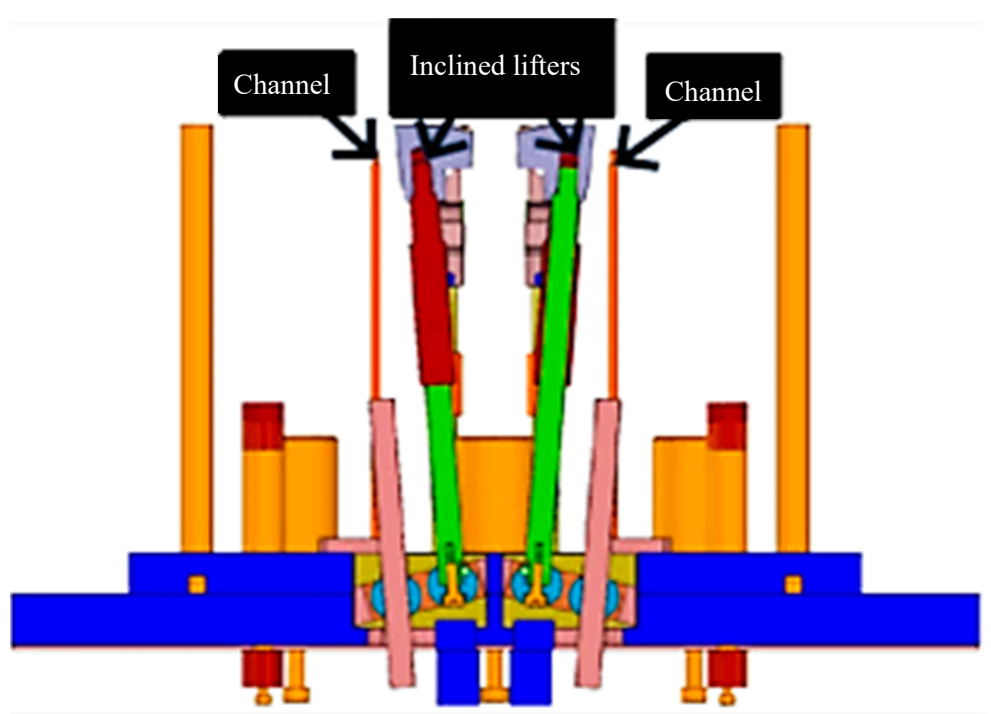

Figure 16. Inclined lifters (sectional view).

After establishing the methodology for moving the molding cavities so that the necessary space for the injection of the second material is created, the mold was built and tested (shown in Figure 17 as three different views of one of the parts produced during the mold's testing phase). This proves that the conceived movement model can be successfully installed in molds for the injection of two or more materials, thus avoiding the use of standard systems that require more space to produce similar effects. This solution also contributes to a more sustainable mold industry, in which less material can be used, obtaining the same final effect.

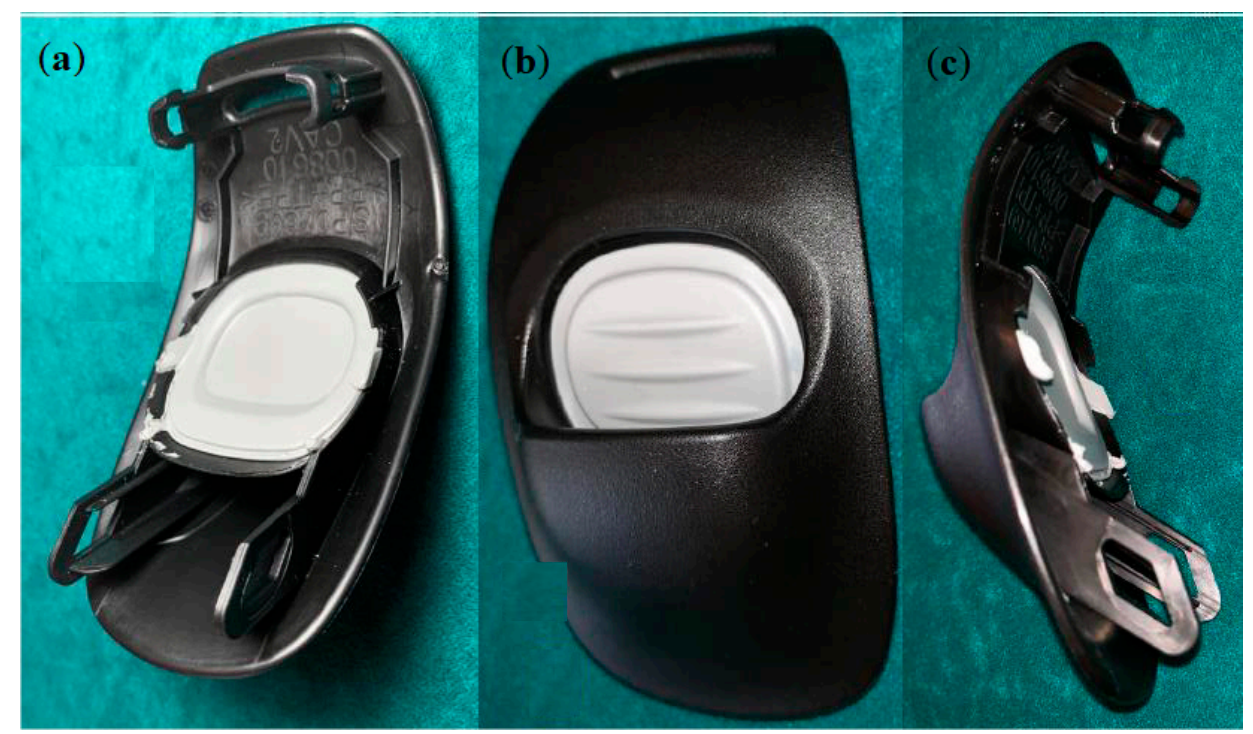

Figure 17. Aspect of the first parts obtained through the mold produced using the movement technique developed by this work: (a) back side of the part; (b) front side of the part; (c) lateral view of the part.

As can be seen in Figures 9 and 14, the movements achieved are of low amplitude, but perfectly sufficient for the desired function. Thus, it was proved that the combination of movements promoted by hydraulic and mechanical means could give rise to the necessary movements in the molds without taking up too much space, making it possible to avoid collisions with other mold devices. This new concept of movements can be applied in the most diverse solutions, adjusting to the space available in the mold. Due to its flexibility, it is no longer necessary to use commercial systems that normally require the application 
of a much larger space, which are also often difficult to adapt to certain mold geometries. The concept can be applied to any mold that presents the need to move part of the cavity to give rise to the injection of a second polymeric material over another injected in the first cycle. From now on, mold designers will be able to adopt this methodology when designing molds, promoting a shortening of the space occupied by the mold, reducing its overall weight and allowing it to be used in smaller injection machines, making the process more economically sustainable.

\section{Discussion}

Extraction operations were typified by different authors, depending on the lesser or greater difficulty of the operation for the extracted geometry part. A good attempt to summarize the various situations was made by Goodship [29], but the cases reported do not include the needs brought by multi-material injections. Regarding the impact on costs, Jones [30] made a good attempt to describe all of the factors affecting the overall cost of the molds, including the maintenance and non-quality costs. Yet, the problems caused by complex and lengthy extraction devices into the mold, with implications for the selection of the injection machine were not reported. Frenkler and Zawistowski [31] addressed a problem similar to that discussed in this work, considering the cost implications of the mold regarding the introduction of hot runners. However, in that case, the analysis was carried out in terms of the cost of the mold, while in the case of the present work the implications are addressed for two factors: direct cost of the mold and cost of operating the mold, since it implies the use of a greater capacity, which also leads to the consumption of a greater volume of energy, thus being less sustainable in service [32]. Goodship and Love [33] published a book regarding the multi-material injection molding, where the core back molding and the rotating molding techniques were described, but the problems related to the eventual collisions and space occupied by the extractors, together with the preparation system for the change of cavity between the first and the second injection, were not discussed. Thus, after a deep search throughout the literature, the subject discussed and developed in this work seems very scarce. This reinforces the novelty of this approach.

The conventional molds that are used to obtain parts by bi-injection have a simple structure, as shown in Figure 18. As previously mentioned, the movements required to operate both injections are usually performed by the employment of lengthy and complex mechanical devices (Figure 1). The use of these components in the molding area causes the dimensions of the mold to increase (to accommodate these components). However, in the case of the developed mold, this occupied space is reduced, because the movements are produced by hydraulic cylinders, which can be placed externally to the main structure of the mold. Indeed, the hydraulic cylinders produce their actuation in the wedge $\left(90^{\circ}\right)$, which avoids the necessity of the same height of the mold. Moreover, the cylinders can be connected externally to the main structure of the mold, which does not consume the volume of the mold, implying a higher volume. The great success of this mold is reflected in the way it performs bi-injection parts using a relatively simple, yet extremely effective, hybrid mechanism combining mechanical and hydraulic movements to move the cavity from the first to the second injection, thus creating the necessary space for the second material to be injected over the first one. This can be performed without changing the external structure of the mold, which remains close to the conventional structure observed in Figure 18. 


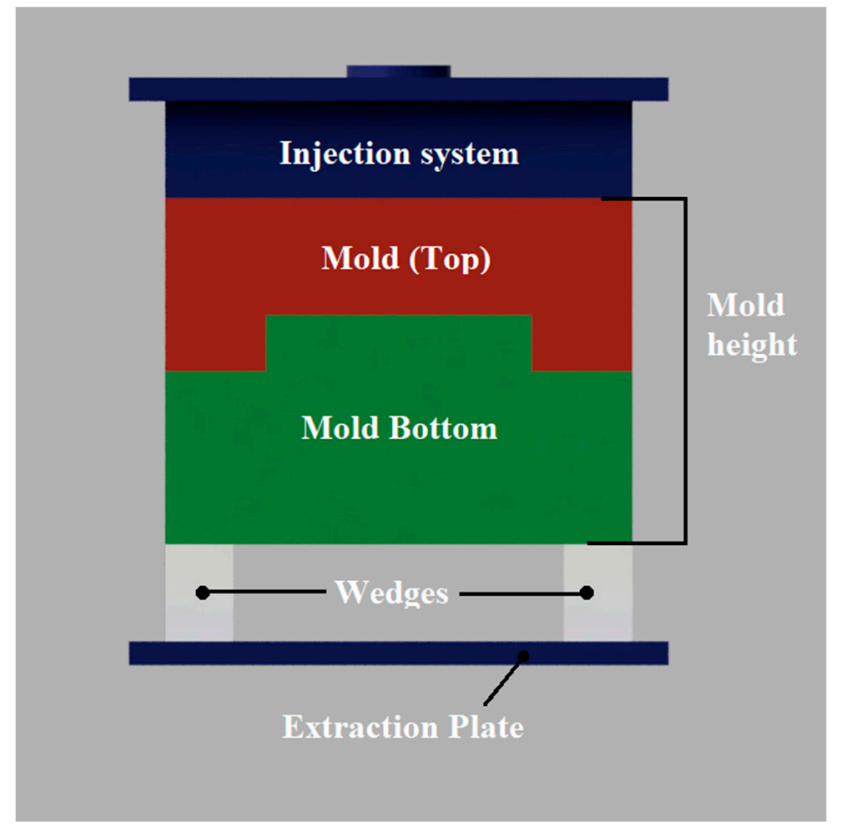

Figure 18. Conventional injection mold structure.

The developed mechanism consists of a horizontal hydraulic movement, which activates a mechanical device in a direction perpendicular to itself (Figure 13, Type-1 cylinder). The device is used to make the cavity movement occupy less space than usual (when compared to the conventionally used extraction devices), allowing for the remaining free space to be used by the extractors/lifters to perform the movement needed between the first and second injection. Because the hydraulic cylinders can be positioned vertically relative to the mold movement (parallel to the base of the mold), they do not require a higher distance between the injection machine plates (by reducing mold height) and can be easily accommodated among the remaining devices needed for extraction. In Table 2, the dimensions of the developed mold are compared against the dimensions of a conventional mold that is required to produce the presented bi-injected parts. A schematic representation of these two molds is illustrated in Figure 19, which shows a reduction in mold dimensions.

Table 2. Mold dimensions for conventional and the developed hybrid movement mold.

\begin{tabular}{cccc}
\hline Mold Type & $\begin{array}{c}\text { Mold Height } \\
(\mathbf{m m})\end{array}$ & $\begin{array}{c}\text { Mold Length } \\
(\mathbf{m m})\end{array}$ & $\begin{array}{c}\text { Mold Width } \\
(\mathbf{m m})\end{array}$ \\
\hline Conventional & 430 & 510 & 580 \\
\hline Hybrid Movement & 370 & 446 & 580 \\
\hline
\end{tabular}

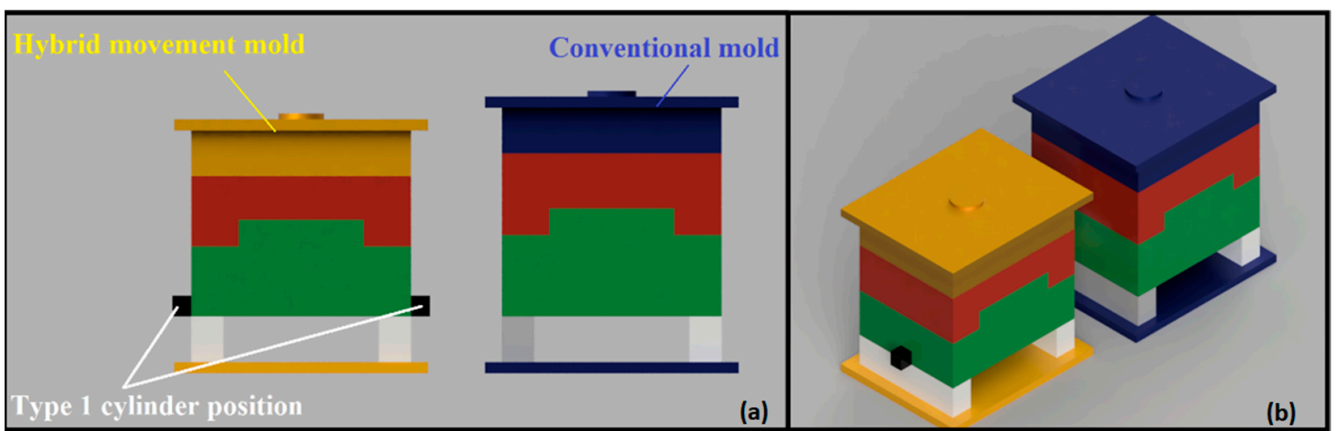

Figure 19. Schematic representation of both mold types (Yellow-designed hybrid movement mold; Blue-conventional mold): Front view of both molds, with the identification of type 1 cylinder positioning (a); Isometric view of both mold types (b). 
Analyzing the values presented in Table 2, an increase of about $33 \%$ in mold volume was observed, significantly reducing the required mold height, while also reducing the required mold length. This mold height reduction is relatively important, as it influences the injection machine selection. With a more compact mold, a smaller machine can be selected (if the required clamping weight is met), effectively reducing operating costs while producing the parts within the requirements.

Another advantage of the developed system is that the cylinders responsible for the mold movements can be installed outside of the mold (Figure 13), and do not require additional mold space to accommodate these components. The positioning of the type 1 cylinders is shown in Figure 19, with the complete system shown in the Figure 20.

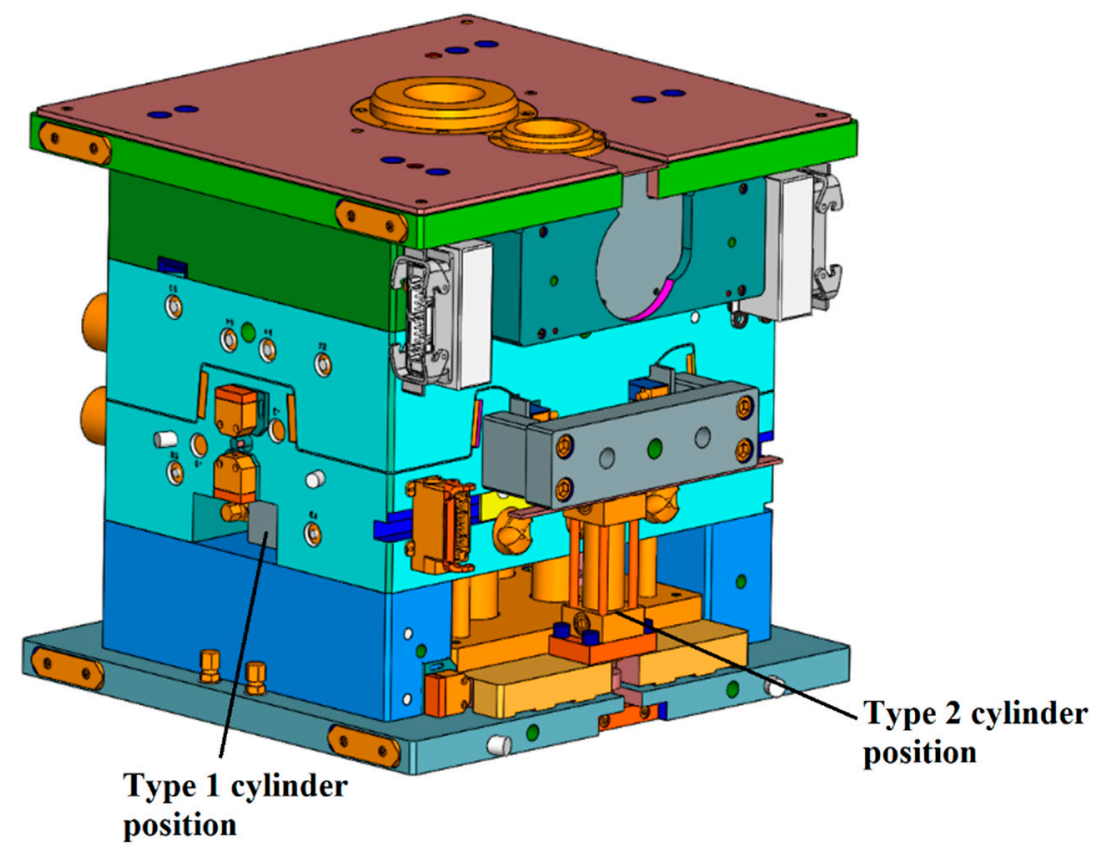

Figure 20. Designed mold structure, with the developed system implemented.

This methodology could be used in various applications, effectively reducing the required mold space for the injected parts obtention. As previously mentioned, this enables the selection of smaller machines with a lower operating cost. In the presented case, a machine with a clamping force of $250 \mathrm{t}$ was used for the developed mold; however, if the conventional mold were to be used, due to the increased mold height, a machine with a clamping force of $350 \mathrm{t}$ would be required to accommodate the mold. The use of this larger machine would cause an increase in the operating cost of about $22 \%$. This value was calculated based on the medium operating cost per hour, associated with each of the machine types. These values are presented in A.U./h (arbitrary units per hour) in Table 3.

Table 3. Operation cost per hour for both of the considered machine types.

\begin{tabular}{cc}
\hline Machine Type & Operation Cost (A.U./h) \\
\hline $350 \mathrm{t}$ (conventional mold) & 76 \\
\hline $250 \mathrm{t}$ (hybrid movement mold) & 59 \\
\hline
\end{tabular}

This highlights the cost effectiveness of this approach; however, this comparison is appliable to the machining operating costs and unrelated to productivity gains.

\section{Conclusions}

The hybrid movement methodology developed through this work allowed for a reduction in needed workspace volume and a reduction in mold volume by about 33\%. The use of smaller mold by implementing the devised methodology, made possible the 
use of a bi-injection machine of $250 \mathrm{t}$ instead of a $350 \mathrm{t}$. This downsizing allowed for a reduction in machine operation costs (operation cost per hour) of around $22 \%$, representing a significant decrease, when compared to the previously adopted system. Moreover, the extraction movements, performed by four lifters per cavity, facilitated the complete extraction of the injected parts, without the risk of part damage and causing very visible marks on the injected parts. Thus, the hybrid methodology applied to the design of molds for multi-material injection molding leads to a more sustainable production system using a more compact mold design, capable of dealing with extraction devices and the movements required by the cavity to enable the injection of the second material.

The part used as an example for the application of this methodology was successfully produced. The proposed system can be applied to any mold for multi-material injection molding, enabling the optimization of mold space, reducing it, and enabling the selection of more profitable and sustainable solutions, especially from an equipment selection standpoint.

Author Contributions: Conceptualization, F.J.G.S., F.d.A. and V.F.C.S.; methodology, F.J.G.S.; software, V.F.C.S.; validation, F.J.G.S., F.d.A. and R.D.S.G.C.; formal analysis, L.P.F; investigation, V.F.C.S.; resources, V.F.C.S.; data curation, R.D.S.G.C.; writing—original draft preparation, F.d.A., F.J.G.S.; writing-review and editing, R.D.S.G.C. and L.P.F.; supervision, F.J.G.S. and F.d.A.; project administration, F.J.G.S., L.P.F., R.D.S.G.C. and F.d.A. All authors have read and agreed to the published version of the manuscript.

Funding: This research received no external funding.

Institutional Review Board Statement: Not applicable.

Informed Consent Statement: Not applicable.

Data Availability Statement: Not applicable.

Acknowledgments: The authors would like to thank the INEGI-Instituto de Ciência e Inovação em Engenharia Mecânica e Engenharia Industrial (Porto, Portugal) for their continuous support.

Conflicts of Interest: The authors declare no conflict of interest.

\section{References}

1. Barbosa, R.C.N.; Campilho, R.D.S.G.; Silva, F.J.G. Injection mold design for a plastic component with blowing agent. Procedia Manuf. 2018, 17, 774-782. [CrossRef]

2. Pinto, H.; Silva, F.J.G. Optimization of die casting process in Zamak alloy. Procedia Manuf. 2017, 11, 517-525. [CrossRef]

3. Nunes, V.; Silva, F.J.G.; Andrade, M.F.; Alexandre, R.; Baptista, A.P.M. Increasing the lifespan of high-pressure die cast molds subjected to severe wear. Surf. Coat. Technol. 2017, 332, 319-331. [CrossRef]

4. Silva, F.J.G.; Campilho, R.D.S.G.; Ferreira, L.P.; Pereira, M.T. Establishing guidelines to improve the high-pressure die casting process of complex aesthetics parts. In Transdisciplinary Engineering Methods for Social Innovation of Industry 4.0; Peruzzini, M., Pellicciari, M., Bil, C., Stjepandić, J., Wognum, N., Eds.; IOP Press: Bristol, UK, 2018. [CrossRef]

5. Pinto, H.A.; Silva, F.J.G.; Martinho, R.P.; Campilho, R.D.S.G.; Pinto, A.G. Improvement and validation of Zamak die cast moulds. Procedia Manuf. 2019, 38, 1547-1557. [CrossRef]

6. Rashid, O.; Low, K.W.Q.; Pittman, J.F.T. Mold cooling in thermoplastics injection molding: Effectiveness and energy efficiency. J. Clean. Prod. 2020, 264, 121375. [CrossRef]

7. Geminger, T.; Jarka, S. Injection Molding of Multimaterial Systems. In Specialized Injection Molding Techniques; Heim, H.-P., Ed.; William Andrew Publishing: Norwich, NY, USA, 2016; pp. 165-210. [CrossRef]

8. Silva, F.; Martinho, R.; Andrade, M.; Baptista, A.; Alexandre, R. Improving the Wear Resistance of Moulds for the Injection of Glass Fibre-Reinforced Plastics Using PVD Coatings: A Comparative Study. Coatings 2017, 7, 28. [CrossRef]

9. Guo, W.; Deng, F.; Meng, Z.; Hua, L.; Mao, H.; Su, J. A hybrid back-propagation neural network and intelligent algorithm combined algorithm for optimizing microcellular foaming injection molding process parameters. J. Manuf. Process. 2020, 50, 528-538. [CrossRef]

10. Guo, F.; Zhou, X.; Liu, J.; Zhang, Y.; Li, D.; Zhou, H. A reinforcement learning decision model for online process parameters optimization from offline data in injection molding. Appl. Soft Comput. 2019, 85, 105828. [CrossRef]

11. Ogorodnyk, O.; Lyngstad, O.V.; Larsen, M.; Martinsen, K. Application of feature selection methods for defining critical parameters in thermoplastic injection molding. Procedia CIRP 2019, 81, 110-114. [CrossRef]

12. Barrière, T.; Gelin, J.C.; Liu, B. Improving moulding design and injection parameters in metal injection moulding by accurate 3D finite element simulation. J. Mater. Process. Technol. 2002, 125-126, 518-524. [CrossRef] 
13. Tang, S.H.; Tan, Y.J.; Sapuan, S.M.; Sulaiman, S.; Ismail, N.; Samin, R. The use of Taguchi method in the design of plastic injection mould for reducing warpage. J. Mater. Process. Technol. 2007, 182, 418-426. [CrossRef]

14. Park, H.-S.; Dang, X.-P. Development of a smart plastic injection mold with conformal cooling channels. Procedia Manuf. 2017, 10, 48-59. [CrossRef]

15. Farotti, E.; Natalini, M. Injection moulding. Injection molding. Influence of process parameters on mechanical properties of polypropylene polymer. A first study. Procedia Struct. Integr. 2018, 8, 256-264. [CrossRef]

16. Zabala, B.; Fernandez, X.; Rodriguez, J.C.; Lopez-Ortega, A.; Fuentes, E.; Bayón, R.; Igartua, A.; Girot, F. Mechanism-based wear models for plastic injection moulds. Wear 2019, 440-441, 203105. [CrossRef]

17. Silva, F.J.G.; Martinho, R.P.; Alexandre, R.J.D.; Baptista, A.P.M. Wear Resistance of TiAlSiN Thin Coatings. J. Nanosci. Nanotechnol. 2012, 12, 9094-9101. [CrossRef]

18. Silva, F.J.G.; Casais, R.C.B.; Martinho, R.P.; Baptista, A.P.M. Mechanical and Tribological Characterization of TiB 2 Thin Films. J. Nanosci. Nanotechnol. 2012, 12, 9187-9194. [CrossRef]

19. Martinho, R.P.; Silva, F.J.G.; Alexandre, R.J.D.; Baptista, A.P.M. TiB 2 Nanostructured Coating for GFRP Injection Moulds J. Nanosci. Nanotechnol 2011, 11, 5374-5382. [CrossRef] [PubMed]

20. Bobzin, K.; Brögelmann, T.; Grundmeier, G.; de los Arcos, T.; Wiesing, M.; Kruppe, N.C. (Cr,Al)N/(Cr,Al)ON Oxy-nitride Coatings deposited by Hybrid dcMS/HPPMS for Plastics Processing Applications. Surf. Coat. Technol. 2016, 308, 394-403. [CrossRef]

21. Silva, F.J.G.; Martinho, R.P.; Baptista, A.P.M. Characterization of laboratory and industrial CrN/CrCN/diamond-like carbon coatings. Thin Solid Film. 2014, 550, 278-284. [CrossRef]

22. Fu, M.W.; Nee, A.Y.C.; Fuh, J.Y.H. The application of surface visibility and moldability to parting line generation. Comput. Aided Des. 2002, 34, 469-480. [CrossRef]

23. Nee, A.Y.C.; Fu, M.W.; Fuh, J.Y.H.; Lee, K.S.; Zhang, Y.F. Determination of Optimal Parting Directions in Plastic Injection Mold Design. CIRP Ann. Manuf. Technol. 1997, 46, 429-432. [CrossRef]

24. Tang, S.H.; Kong, Y.M.; Sapuan, S.M.; Samin, R.; Sulaiman, S. Design and thermal analysis of plastic injection mould. J. Mater. Process. Technol. 2006, 171, 259-267. [CrossRef]

25. Mercado-Colmenero, J.M.; Rubio-Paramio, M.A.; Vizan-Idoipe, A.; Martin-Doñate, C. A new procedure for the automated design of ejection systems in injection molds. Robot. Comput. Integr. Manuf. 2017, 46, 68-85. [CrossRef]

26. Mercado-Colmenero, J.M.; Rubio-Paramio, M.A.; Marquez-Sevillano, J.J.; Martin-Doñate, C. A new method for the automated design of cooling systems in injection molds. Comput. Aided Des. 2018, 104, 60-86. [CrossRef]

27. Gouker, R.M.; Gupta, S.K.; Bruck, H.A.; Holzschuh, T. Manufacturing of multi-material compliant mechanisms using multimaterial molding. Int. J. Adv. Manuf. Technol. 2006, 30, 1049-1075. [CrossRef]

28. LANXESS Corporation. Engineering Plastics_Part and Mold Design. A Design Guide. Available online: https://techcenter. lanxess.com/scp/americas/en/docguard/Part_and_Mold_Design_Guide.pdf?docId=77015 (accessed on 15 March 2020).

29. Goodship, V. Practical Guide to Injection Moulding; Rapra Technology Limited: Shropshire, UK, 2004; p. 64. ISBN 1-85957-444-0.

30. Jones, P. Budgeting, Costing and Estimating for the Injection Moulding Industry; iSmithers: Shropshire, UK, 2009; p. 33. ISBN 978-1-84735-211-8.

31. Frenkler, D.; Zawistowski, H. Hot Runners in Injection Moulds; Rapra Technology Limited: Shropshire, UK, 2001; p. 29. ISBN 1-85957-208-1.

32. Silva, F.J.G.; Gouveia, R.M. Cleaner Production-Toward a Better Future; Springer Nature: Cham, Switzerland, 2020; pp. 247-280. ISBN 978-3-030-23164-4.

33. Goodship, V.; Love, J.C. Multi-Material Injection Moulding; Rapra Technology Limited: Shropshire, UK, 2002 ; pp. 22-31. ISBN 1-85957-327-4. 